\title{
A study of maternal near miss at a district teaching hospital: a retrospective observational study
}

\author{
Manjunatha S., Harsha T. N.*, Damayanthi H. R.
}

\author{
Department of Obstetrics and Gynecology, Kodagu Institute of Medical Sciences Teaching Hospital, Madikeri, \\ Karnataka, India
}

Received: 13 March 2018

Accepted: 17 March 2018

\author{
*Correspondence: \\ Dr. Harsha T. N., \\ E-mail: drharsha.tn@gmail.com
}

Copyright: ( ) the author(s), publisher and licensee Medip Academy. This is an open-access article distributed under the terms of the Creative Commons Attribution Non-Commercial License, which permits unrestricted non-commercial use, distribution, and reproduction in any medium, provided the original work is properly cited.

\begin{abstract}
Background: Maternal health is an integral part of health care system. Maternal mortality is an indicator of maternal health and health care delivery system. Severe morbid conditions require comprehensive approach. Hence the concept of Maternal Near Miss (MNM) has emerged. The data of maternal near miss helps to reduce the maternal death and helps to achieve the goals related to reduce the maternal mortality rate of the country as well as the world and to improve the quality of life of the woman population by a quality care. Objectives of present study were to identify and analyze the strategies undertaken in the management of maternal near miss and outcome, measures to improve the quality of care and to assess the various indicators of MNM.

Methods: With the permission from the hospital administrators and after taking the ethical clearance from the institutional ethical committee, a retrospective observational study was conducted for the period of one year between January 2016 to December 2016 at district teaching hospital of Kodagu Institute of Medical Sciences, Madikeri, by collecting data from hospital records. Admissions to the ICU as well as wards which fit in to the WHO maternal near miss criteria were included and studied.

Results: WHO criteria for the MNM was followed. In present study, there were 25 MNM cases and four Maternal Deaths out of 3347 live births giving a maternal mortality ratio of 119/100000 live births (LB), Maternal Near Miss ratio of 7.46/1000LB, MNM:1MD ratio is 6.25 and mortality index (MI) is $13.79 \%$. Twenty five cases of obstetric emergencies with serious concerns for maternal health were selected out of 97 cases who met the WHO criteria for MNM (25.77\%). Twelve cases (48\%) received multiple blood-transfusions, 8 cases (32\%) of sepsis, 7 (28\%) of PPH, and $5(20 \%)$ of hypertensive disorder of pregnancy (pre-eclampsia, eclampsia). There were 12 cases $(48 \%)$ that had more than one inclusion criteria. Surgical intervention was required in $8(32 \%)$ i.e. 2 peripartum hysterectomies, 2 laparotomies, 1 manual removal of placenta, 1 uterine reposition and 2 traumatic PPH repair.

Conclusions: Maternal-Near-Miss (MNM/SAMM) and its relation to maternal mortality contribute as sensitive measures of pregnancy outcome than mortality alone. Proper documentation is of paramount importance in analysis of data, to make conclusions and recommendation. Prospective structured study is required to get a clear picture and to suggest corrective measures which can be taken as far as obstetric care is concerned, to reduce maternal mortality and to achieve the sustainable developmental Goal (SDG) of maternal mortality ratio <70/100000 LB by 2030 .
\end{abstract}

Keywords: Maternal near miss, Maternal mortality, Severe acute maternal morbidity

\section{INTRODUCTION}

Maternal mortality data in practical terms is the tip of an iceberg and the maternal near miss data is invisible and which is very important tool to reduce the maternal mortality. Knowing the causes for the maternal death and analysing the modes of treatment which followed to save the life of pregnant women is an important tool which constitutes the maternal near miss cases. Process of pregnancy and labour is considered to be another birth to 
women. Providing the good health care and managing the complications due to childbirth is an at most important challenge in present scenario of the healthcare system. Every woman can experience sudden and unexpected complications during pregnancy, child birth and just after delivery. Survival of a pregnant woman is dependent on the disease, her basic health, the health care facilities and the personnel of the health care.

Maternal mortality is one of the important indicators used for the measurement of maternal health. Improvement of maternal health is one of the millennium development goals, MDG 5 with Target 5 A that calls for the reduction of maternal mortality ratio by three quarters (75\%) between 1990 and 2015. Since 1990, though maternal deaths world-wide have dropped by $47 \%$, the number of maternal deaths in developing countries remains high. The global maternal mortality ratio is $210 / 100,000$ births while it is about 240 in developing countries as compared to $14 / 100,000$ in developed countries. India has also reported a decline from $437 / 100000 \mathrm{LB}$ in 1990-991 to $178 / 100000$ LB in $2010-12 .^{1,2}$

To overcome this challenge, severe acute maternal morbidity (SAMM) and now called Maternal Near Miss (MNM) and its review is introduced in maternal health care to complement information obtained with review of maternal deaths.

Auditing maternal deaths is an approach commonly used for assessing the quality of care in order to address any identified weakness or failure within the system and take corrective action. Studying cases of women who nearly died but survived a complication during pregnancy, childbirth or postpartum are increasingly recognized as a useful means to examine the quality of obstetric care. ${ }^{3}$

Maternal Near Miss defined variously over years. First to use the term defined Near miss morbidity a narrow category of morbidity encompassing potentially life threatening episodes. ${ }^{4}$ A Near miss describes a patient with an acute organ system dysfunction, which if not treated appropriately could result in death. ${ }^{5}$ All- women admitted for ICU in pregnancy or up to 42 day postpartum are considered as near-miss maternal mortality. ${ }^{6}$ Severe Acute Maternal Morbidity (SAMM) also known as "near-miss" case means a woman with organ dysfunction or failure who would have died had it not been that luck or good care was on her side. A nearmiss case was defined as "any pregnant or recently delivered or aborted woman whose immediate survival is threatened and who survives by chance or because of the hospital care received. ${ }^{7}$ A near-miss case was defined as "any pregnant or recently delivered or aborted woman whose immediate survival is threatened and who survives by chance or because of the hospital care received. ${ }^{8}$ There were some controversies on the definitions because of the differences in availability health facilities between developed and developed countries. On clarity WHO standardised the definition of the maternal near miss as a woman who nearly died but survived a complication that occurred during pregnancy, childbirth or within 42 days of termination of pregnancy and has given the criteria for maternal near miss. ${ }^{1}$ MOHFW Govt. of INDIA: defines a MNM case as a woman who survives life threatening conditions during pregnancy, abortion, and childbirth or within 42 days of pregnancy termination, irrespective of receiving emergency medical/surgical interventions. ${ }^{2}$

Maternal near miss shares same pathway and pathological processes as maternal death. Also, the major reasons and causes are same for both, so review of Maternal near miss cases is likely to yield valuable information regarding severe morbidity, which, if untreated may lead to maternal death.

The data, statistics and strategies of MNM is the need of hour to reduce the maternal mortality and to improve the maternal health. Present study is taken up to draw the current MNM data in our teaching hospital by which adopting and improving the treatment strategies for reducing the maternal mortality to achieve the sustainable developmental goal by 2030 .

\section{METHODS}

A Retrospective observational study was conducted after taking the permission from the hospital administrators and after the approval from the institutional Ethical committee. The case sheets of 3347 cases between the period January 2016 and December 2016 collected from the hospital Medical records and studied. Data was analysed in terms of obstetric emergencies (preeclampsia, eclampsia, ante partum haemorrhage, post partum haemorrhage, ectopic pregnancy etc.) and their management medically and surgically, antenatal and postnatal cases, parity, gestational age $\leq 34$ weeks to 40 weeks, registration of cases (booked, unbooked and referred cases), modes of delivery( vaginal, Caesarean, home), duration of hospital stay ( $\leq 24 \mathrm{hrs}-13$ days), duration of ICU stay ( $\leq 24 \mathrm{hrs}-4$ days). The study was conducted as per the criteria defined by the WHO. The following criteria of WHO were included in present study.

\section{- Clinical criteria}

- Laboratory criteria

- Management criteria

Slight modification in the criteria done with respect to blood transfusions. We have included transfusions 3-4 against 5 transfusions given by the WHO. Cases admitted in ICU as well as Ward also considered. The following indicators were calculated.

- Maternal death (maternal mortality ratio)

- Maternal near miss ratio

- MNM:1MD ratio

- Mortality index

- SMOR 


\section{Statistical analysis}

The data was entered into the Microsoft excel sheet and the percentage was calculated.

\section{RESULTS}

A retrospective observational study was conducted, and data was collected from case sheets of 3347 live births (LB) in a year between the period of January 2016 and December 2016. Out of 3347 live births 04 were maternal deaths $(119 / 100000 \mathrm{LB})$.

Out of 97 obstetrics emergency cases 25 cases $(25.77 \%)$ were selected for the study who met the WHO criteria for the MNM, (Table 1).

Table 1: Selection of MNM cases.

\begin{tabular}{|c|c|c|c|}
\hline \multirow{2}{*}{$\begin{array}{l}\text { Total Live Births } \\
\text { (Jan 2016-Dec } \\
\text { 2016) }\end{array}$} & Vaginal & 1812 & \multirow[b]{2}{*}{3347} \\
\hline & Caesarean & 1535 & \\
\hline Total MNM cases & & & 25 \\
\hline \multirow[t]{2}{*}{$\begin{array}{l}\text { Total maternal } \\
\text { deaths }\end{array}$} & & & 04 \\
\hline & & Total & $\begin{array}{l}\text { Taken for } \\
\text { MNM }\end{array}$ \\
\hline ICU admission & & 43 & 22 \\
\hline $\begin{array}{l}\text { MNM cases with } \\
\text { ICU admission }\end{array}$ & \multicolumn{2}{|c|}{$\begin{array}{l}\text { MNM cases without } \\
\text { ICU admission }\end{array}$} & $\begin{array}{l}\text { Total } \\
\text { MNM } \\
\text { cases }\end{array}$ \\
\hline 22 & 03 & & 25 \\
\hline
\end{tabular}

Out of 25 cases of MNM $22(88 \%)$ cases were taken from ICU admission and 03 (12\%) from the ward. maternal near miss ratio of $7.46 / 1000 \mathrm{LB}$. MNM:1MD ratio is 6.25 This means for every maternal death there were 6.25 cases of MNM. Mortality Index (MI) is $13.79 \%$.

Table 2: The age wise distribution of MNM.

\begin{tabular}{|lll|}
\hline Age (Yrs) & No. of case $(\mathbf{N}=\mathbf{2 5})$ & $\%$ \\
\hline$\leq 20$ & 02 & 8 \\
\hline $21-25$ & 10 & 40 \\
\hline $26-30$ & 09 & 36 \\
\hline $31-35$ & 03 & 12 \\
\hline $36-40$ & 01 & 4 \\
\hline Total & 25 & \\
\hline
\end{tabular}

There were $8 \%(02)$ cases in $\leq 20$ years of age, $40 \%$ (10) in 21-25yeras of age, 36\% (09) in 26-30 years, $12 \%(03)$ in 31-35 year age group and $4 \%(01)$ in 36-40 age group (Table 2).

There were $80 \%$ (20) of antenatal cases and 20\% (05) of cases were postnatal cases (Table 3). In antenatal cases $55 \%$ (11) were Gravida 1, 35\% (07) cases were Gravida 2 and $10 \%$ (02) were Gravida 3 (Table 4).
Table 3: Distribution of cases.

\begin{tabular}{|lll|}
\hline Type & $\mathbf{N}=25$ & $\%$ \\
\hline ANC & 20 & 80 \\
\hline PNC & 05 & 20 \\
\hline Total & 25 & 100 \\
\hline
\end{tabular}

Table 4: Distribution of cases by parity.

\begin{tabular}{|lll|}
\hline Parity & $\mathbf{N}=20$ & $\%$ \\
\hline G1 & 11 & 55 \\
\hline G2 & 07 & 35 \\
\hline G3 & 02 & 10 \\
\hline Total & 20 & 100 \\
\hline
\end{tabular}

There were $18 \%(03)$ cases in the Gestational age group of $35-<37 \mathrm{wks}, 6 \%(01)$ in $37-<38 w \mathrm{ws}, 23 \%(04)$ in $38-$ $<39 w k s, 47 \%(08)$ in $39-<40 w k s$ and $06 \%(01)$ cases in $>40$ wks (Table 5).

Table 5: Distribution of cases by gestational age in weeks.

\begin{tabular}{|c|c|c|}
\hline GA (Weeks) & $\mathrm{N}=17$ & $\%$ \\
\hline$\leq 34$ & 0 & 00 \\
\hline $35-<37$ & 3 & 18 \\
\hline $37-<38$ & 1 & 06 \\
\hline $38-<39$ & 4 & 23 \\
\hline $39-40$ & 8 & 47 \\
\hline$>40$ & 1 & 06 \\
\hline
\end{tabular}

$52 \%$ (13) of cases were booked cases, 36\% (09) of cases were unbooked and 12(03) cases were referred to our hospital (Table 6).

Table 6: Distribution of cases by registration with our hospital.

\begin{tabular}{|lll|}
\hline Status & $\mathbf{N}=\mathbf{2 5}$ & $\%$ \\
\hline Booked & 13 & 52 \\
\hline Unbooked & 09 & 36 \\
\hline Referred in & 03 & 12 \\
\hline Total & 25 & 100 \\
\hline
\end{tabular}

Table 7: Distribution of cases in various modes of delivery.

\begin{tabular}{|llll|}
\hline Mode & $\begin{array}{l}\text { Our } \\
\text { hospital } \\
(\mathbf{N}=17)\end{array}$ & $\begin{array}{l}\text { Outside our } \\
\text { hospital } \\
(\mathbf{N}=5)\end{array}$ & Total \\
\hline Vaginal & 04 & 03 & 07 \\
\hline $\begin{array}{l}\text { Caesarean } \\
\text { delivery }\end{array}$ & 13 & - & 13 \\
\hline Home & - & 02 & 02 \\
\hline $\begin{array}{l}\text { Ectopic pregnancy } \\
\text { and incomplete } \\
\text { abortion }\end{array}$ & 03 & & 03 \\
\hline Total & 20 & 05 & 25 \\
\hline
\end{tabular}


In the MNM cases selected, Total 07 cases of vaginal deliveries selected in which 04 were conducted at our hospital and 03 were conducted in other hospitals and referred to our hospital. Total 13 cases of caesarean section cases selected which were conducted at our hospital. 02 deliveries were conducted at home and referred to our hospital, 02 cases of ruptured ectopic pregnancy and 01 case of hypovolumic shock due to incomplete abortion (Table 7).

Table 8: Distribution of cases in various modes of delivery.

\begin{tabular}{|lllll|}
\hline & $\begin{array}{l}\text { Yelika } \\
\text { r et al }\end{array}$ & $\begin{array}{l}\text { Ranatunga } \\
\text { G.A. et al }\end{array}$ & $\begin{array}{l}\text { D'Cunha } \\
\text { P. }\end{array}$ & $\begin{array}{l}\text { Present } \\
\text { study }\end{array}$ \\
$\begin{array}{l}\text { Duration } \\
\text { of study } \\
\text { (months) }\end{array}$ & 29 & 12 & 12 & 12 \\
\hline $\begin{array}{l}\text { Total live } \\
\text { births }\end{array}$ & 35564 & 16511 & 3142 & 3347 \\
\hline $\begin{array}{l}\text { MNM } \\
\text { cases }\end{array}$ & 416 & 91 & 87 & 25 \\
\hline MD & 84 & 05 & 05 & 04 \\
\hline $\begin{array}{l}\text { MMR } \\
\text { (per }\end{array}$ & 236 & 30.3 & 159 & 119 \\
$\begin{array}{l}\text { 100000 } \\
\text { live birth) }\end{array}$ & & & & \\
\hline $\begin{array}{l}\text { MNM R } \\
\text { (Per 1000 }\end{array}$ & 11.69 & 5.5 & 27.8 & 7.46 \\
live birth) & & & $17.6: 1$ & $6.25: 1$ \\
\hline $\begin{array}{l}\text { MNM: } \\
\text { 1MD }\end{array}$ & $4.95: 1$ & $18.2: 1$ & $5.43 \%$ & $13.79 \%$ \\
\hline $\begin{array}{l}\text { MI } \\
\text { SMOR } \\
\text { (Per 1000 }\end{array}$ & 14.06 & 5.81 & 29.28 & 8.66 \\
\hline $\begin{array}{l}\text { live birth) } \\
\text { 1ive }\end{array}$ & $5.2 \%$ & & \\
\hline
\end{tabular}

Table 9: Comparative statistics in similar studies.

\begin{tabular}{|llll|}
\hline Mode of delivery & $\begin{array}{l}\text { Yelikar } \\
\text { et al }\end{array}$ & $\begin{array}{l}\text { Ranatunga } \\
\text { GA et al }\end{array}$ & $\begin{array}{l}\text { Present } \\
\text { study }\end{array}$ \\
\hline Vaginal & $52.29 \%$ & $25.7 \%$ & $23.53 \%$ \\
\hline $\begin{array}{l}\text { Instrumental } \\
\text { Caesarean delivery }\end{array}$ & $30.46 \%$ & $68.5 \%$ & $76.47 \%$ \\
\hline Registration status & & & \\
\hline Booked & $17.7 \%$ & - & $52 \%$ \\
\hline Unbooked & $82.21 \%$ & - & $36 \%$ \\
\hline Referred in & - & - & $12 \%$ \\
\hline Parity & & & \\
\hline Primigravida & $46.34 \%$ & $38.5 \%$ & $55 \%$ \\
\hline Multigravida & $53.66 \%$ & $61.5 \%$ & $45 \%$ \\
\hline Age & & & \\
\hline$\leq 19$ & $5.28 \%$ & - & $8 \%$ \\
\hline $20-29$ & $48.5 \%$ & - & $76 \%$ \\
\hline$\geq 30$ & $46.1 \%$ & - & $16 \%$ \\
\hline
\end{tabular}

Twelve percentage (03) of cases have stayed in the hospital for less than 24hrs, $4 \%$ (01) for 1-2days, $20 \%$ (05) for 3-6 days, $48 \%$ (12) for 7-10 days, and 16\% (04) stayed in the hospital for 11-13 days and survived (Table
8). Duration of stay in ICU, $24 \%$ (06) of cases stayed for $<24 \mathrm{hrs}, 24 \%$ (06) for 1-2 days, $44 \%$ (11) of cases for 2-3 days and $8 \%(02)$ cases stayed in the ICU for 3-4 days (Table 9).

12 cases (48\%) were managed by multiple bloodtransfusion. 8 cases $(32 \%)$ of sepsis, 7 cases $(28 \%)$ of $\mathrm{PPH}, 5$ cases $(20 \%)$ of hypertensive disorder of pregnancy (pre-eclampsia, eclampsia) There were 12 cases $(48 \%)$ that had more than one inclusion criteria Surgical intervention (s) were required in 8 cases $(32 \%)$ (i.e. 2 peripartum hysterectomies, 2 laparotomies, 1 MRP, 1 uterine reposition and 2 traumatic PPH repair).

\section{DISCUSSION}

In our study, there were 25 Maternal-Near-Miss (MNM) cases and four maternal deaths out of 3347 live births which fit into the maternal near miss cases criteria of the WHO and these cases were studied in detail. 04 maternal deaths out of 3347 live births in that year giving Maternal mortality ratio of $119 / 100,000$ live births (LB) at our institution which is very low compared to the national statistics (current MMR of India is 174/100000 LBs and near to the United Nations SDG by 2030 which is $70 / 100000 .^{2}$

Maternal near miss ratio is 7.46/1000LB at our hospital. In a similar study done by Yelikar et al, the MNM-ratio is $11.69 / 1000 \mathrm{LB}$ which is slightly higher than our institution probably because of higher sample size $(n=416$ cases), and in a study by Ranatunga GA et al 5.5/1000LB which is slightly lower compare to our study $(n=91) .9,10$

MNM: $1 \mathrm{MD}$ ratio is 6.25 this means for every maternal death there were 6.25 cases of MNM. In study of Yelikar et al this ratio is 4.95 , and in the study of GA Ranatunga et al this ratio is 18.2 with a good significant rate., ${ }^{9,10}$ Siddiqui et al, Galvão et al, and Ps et al reported the maternal mortality to near miss ratio 5.8, 4.5, and 5.6 respectively which is consistent with present study. ${ }^{10-12}$

Mortality index (MI) in this study is $13.79 \%$ which is high compared to the study done by Ranatunga et al study the MI is $5.2 \%$. High mortality index shows that the quality of health care system is low and vice versa. ${ }^{9,10}$ Author in developing countries need to improve the health care system to improve the quality of life. High mortality index in our study may be because of pre-health conditions of the mother, not regular for the antenatal check-up and non-institutional deliveries without supervision. All these comparisons are shown in the Table 8 .

Twenty-five cases of obstetric emergencies with serious concerns for maternal health were selected out of 97 cases who met the WHO criteria for MNM $(25.77 \%)$.

Twelve cases (48\%) were managed by multiple bloodtransfusion and components transfusion which is highest 
percentage in our study. Similarly, in Yelikar et al. study highest percentage of MNM cases managed by multiple blood component transfusion which is around $86 \%$ of cases. $^{9}$ Huseyin et al reported transfusion of blood products in $40 \% .^{13}$ This shows the cases related to blood transfusion like $\mathrm{PPH}$ to save the mother are more common causes of maternal death and having the blood and its components in the blood bank and timely management can save the mothers. These cases were well managed by our hospital.

Eight cases $(32 \%)$ of sepsis which was the reason for the prolonged hospital stay and morbidity of the women. 7 cases $(28 \%)$ of PPH which were managed surgically as well as medically, 5 cases $(20 \%)$ of hypertensive disorder of pregnancy (pre-eclampsia, eclampsia) were managed successfully in our hospital with ICU care and ward care. In a study by Yelikar et al the MNM cases were more with hypertensive disorders like eclampsia and preeclampsia. ${ }^{9}$ Similar observation of hypertensive disorders are the leading causes for the maternal illness were found in Upadhyay et al and Huseyin et al. ${ }^{13,14}$ Where as in present study the percentage of hypertensive disorder in pregnancy are least which shows that better antenatal care at our hospital.

There were 12 cases (48\%) that had more than one inclusion criteria. Similary in Ranatunga et al study $45 \%$ of cases (41 out of 91 cases) had more than one criterion. $^{10}$

Surgical intervention(s) were required in 8 cases $(32 \%)$ (i.e. 2 peripartum hysterectomies, 2 laparotomies, $1 \mathrm{MRP}$, 1 uterine reposition and 2 traumatic $\mathrm{PPH}$ repair). Twenty three percentage of cases were required the surgical interventions in a study by Yelikar et al slightly lesser than present study. ${ }^{9}$

Other parameters of the study like mode of delivery, registration status, parity of the mother and age of the subjects included were compared with the other studies and shown in Table 10. ${ }^{9,10}$ Rate of MNM cases is more in the caesarean mode of delivery cases compared to other studies and in the vaginal mode of deliveries the cases going for MNM is less compared to other studies. Surgical procedures have more morbidity compared to normal deliveries.

MNM cases are more in booked cases compared to unbooked cases in the studies as well as other studies compared..$^{9,10}$ In the study of Yaliker et al the MNM cases are more in unbooked cases $(82 \%)$ compared to booked cases which is usually acceptable. ${ }^{9}$ Statistics of our study signals that we need to give more care for the booked cases.

MNM cases are more in Primigravida compared Yelikar et al and Ranatunga GD et al studies. ${ }^{9,10}$ Primigravida cases need to be given more care in our hospital. Whereas
MNM incidence in multigravida is less compared to other studies. ${ }^{9,10}$

More MNM cases are found in the 20-29 age groups which is similar compared to other studies. ${ }^{9}$

\section{CONCLUSION}

MNM-R is an eminent adjunctive strategy to help identify gaps in health service provision. MNM-R and MDR are complementary to each other. The current MDR format is not equipped to gather information on those pregnant women who delivered through complications and just about averted mortality. Hence, investigating MNM cases aids in taking measures for further amendment of service delivery and programs. When used together, they help in recognizing the contributory factors of maternal deaths so that appropriate actions can be adopted at community and health systems level. MNM is a vital tool that can go a long way in reducing maternal mortality.

\section{Funding: No funding sources}

Conflict of interest: None declared

Ethical approval: The study was approved by the Institutional Ethics Committee

\section{REFERENCES}

1. WHO. World Health Statistics 2014. Fact Sheets. Geneva: World Health Organization; 2009 and 2014. Available at http://apps.who.int/iris/bitstream/10665/112738/1/97 89240692671_eng.pdf

2. National Technical Group(NTG), NHM (MOHFW) GOI. 2013-14. Available at https://mohfw.gov.in/aboutus/departments/departments-health-and-familywelfare/principal-accounts-office/financial-year2013-14.

3. Ranatunga GA, Akbar JF, Samarathunga S, Perera YAG, Kariyawasam L, Kumarasiri JM. Severe acute maternal morbidity in a tertiary care institution. SLJOG. 2012;34:135-43.

4. Stones W, Lim W, Farook A, Kelly M. An investigation of maternal morbidity with the identification of life threatening "near-miss" episodes. Health trends. 1991;23:13-5.

5. Mantel GD, Buchmann E, Rees H. Severe acute maternal morbidity. British J Obstet Gynaecol. 1998;105(9):985-90.

6. Murphy DJ, Charlett P. Cohort study of near miss maternal mortality and subsequent reproductive onteome. Eur J Obstet Gynaecol Reprod Biol. 2002;102:173-8.

7. 7Pattinson RC, Vandecruys HI, Macdonald AP, Mantel GD Why do women die during childbirth 2001. Available at http: // www. Scienceinafrica. Co.za/2001/august/mothers.htm 
8. Sahel A, Brouwere VD, Lardi M, Lerberghe WV, Ronsmans C, Filippi V. Obstetric catastrophies barely just avoided: near misses in Moroccan hospital. Sante. 2001;11:229-35.

9. Yelikar KA, Deshpande SS, Deshmukh SF. Study of severe acute maternal morbidity in tertiary care centre. Int J Scient Study. 2015;3(5):36-40.

10. Siddiqui SA, Soomro N, Shabih-ul-Hasnain F. Severe obstetric morbidity and its outcome in patients presenting in a tertiary care hospital of Karachi. J Pak Med Assoc. 2012;62:226-31

11. Galvão LP, Alvim-Pereira F, de Mendonça CM, Menezes FE, Góis KA, Ribeiro RF Jr, et al. The prevalence of severe maternal morbidity and near miss and associated factors in Sergipe, Northeast Brazil. BMC Pregnancy Childbirth. 2014;14:25

12. Ps R, Verma S, Rai L, Kumar P, Pai MV, Shetty J. "Near miss" obstetric events and maternal deaths in a tertiary care hospital: An audit. J Pregnancy. 2013;2013:393758.

13. Huseyin C, Cihan K, Ramazan A, Ziya YY, Murat E, Levent Y. Near miss obstetric cases: 4 years experience of a tertiary center. Gynecol Obstet Reprod Med. 2013;19:19-22.

14. Upadhyaya I, Chaudhary P. Severe acute maternal morbidity and intensive care in Paropkar maternity and women's hospital. NJOG. 2013;8:38-41.

Cite this article as: Manjunatha $\mathrm{S}$, Harsha TN,

Damayanthi HR. A study of maternal near miss at a district teaching hospital: a retrospective observational study. Int J Reprod Contracept Obstet Gynecol 2018;7:1421-6. 